\title{
Benzoxazinoids - protective secondary metabolites in cereals: Biochemistry and genetic control
}

\author{
Sanja Mikić ${ }^{1 *}$. Shakoor Ahmad ${ }^{2}$ \\ ${ }^{1}$ Institute of Field and Vegetable Crops, Maksima Gorkog 30, Novi Sad, Serbia \\ ${ }^{2}$ University of Agriculture, Faculty of Animal Husbandry and Veterinary Sciences, Department of Animal Health, Peshawar, Pakistan
}

\begin{abstract}
Summary: Benzoxazinoids (1,4-benzoxazin-3 $(4 \mathrm{H})$-one derivatives, BXs) are plant secondary metabolites that play a crucial role in plant resistance to insects, fungi, bacteria and nematodes, and in weed suppression during early plant life. These biochemicals are constitutive compounds found in some members of the family Poaceae and have been studied in detail in maize (Zea mays L.), wheat (Triticum aestivum L.) and rye (Secale cereale L.). The most effective allelopathic benzoxazinoids are 2,4-dihydroxy-7-methoxy-2H-1,4-benzoxazin-3(4H)-one (DIMBOA) and 2,4dihydroxy-1,4-benzoxazin-3-one (DIBOA), classified as hydroxamic acids. Aiming to draw attention to the importance of BXs in plant defence and their potential application in cereal protection, this review summarises the recent findings in genetic control, biochemical pathways, and the mode of action of these secondary metabolites and addresses unresolved questions related to BXs.

Key words: benzoxazinoids, biochemical pathways, DIMBOA, genetic control, maize, plant defence, resistance, rye,
\end{abstract} secondary metabolites, wheat

\section{Biochemical properties and biological functions of benzoxazinoids}

Plant secondary metabolites are phytochemicals that are not essential for plant growth, development and reproduction, but facilitate those processes, mainly via signalling and regulation of primary metabolism and by providing defence against pests and pathogens. Benzoxazinoids (1,4-benzoxazin-3(4H)-one derivatives, $\mathrm{BXs})$ are protective and allelopathic secondary metabolites that have antifungal, antibacterial, insecticidal, antifeedant and phytotoxic properties. They are found sporadically in several phylogenetically unrelated non-crop dicot species that belong to families Plantaginaceae, Ranunculaceae, Acanthaceae, Lamiaceae, and Scrophulariaceae (Dick et al., 2012). In monocots, BXs are found only in family Poaceae, within two subfamilies Pooideae and Panicoideae, including important crops, such as maize (Zea mays L.), wheat (Triticum aestivum L.) and rye (Secale cereale L.). Considering the economic importance of the

Corresponding author:

sanja.mikic@ifvcns.ns.ac.rs

Acknowledgements:

This study was funded by Ministry of Education, Science and Technological Development of the Republic of Serbia, under the project TR31073. agricultural crop species, this review will summarise the recent findings focusing mainly on these cereals.

Benzoxazinoids are chemically classified into three groups: hydroxamic acids, lactams and benzoxazolinones (Table 1). These chemicals may be in a form of inactive glucoside or bioactive aglycone, depending on whether they contain a sugar group, glycone, or not. The hydroxamic acids and lactams are collectively referred to as benzoxazinones. The most common hydroxamic acids are aglycones DIBOA and its methoxy derivate DIMBOA. Both of these acids can also have their glucoside forms. In comparison to hydroxamic acids, lactams, such as HBOA and its methoxy derivate HMBOA, together with their glucosides, lack hydroxyl group at C-4 position, whereas benzoxazolinones (i.e. BOA and its methoxy derivate MBOA) are characterised with a 5-atom cyclic amide. The chlorinated derivatives of $\mathrm{BXs}$ can also naturally occur in some plants. Besides, the natural benzoxazinones served as a model to produce their synthetic derivatives by the substitution of different functional groups of the basic benzoxazinone skeleton (Macías et al., 2010).

The toxicity of BXs is manifested in the NADH oxidation of cell wall peroxidases, accumulation of hydrogen peroxide, lignification of cell wall, reduced chlorophyll production, lipid metabolism disorder, inhibition of trypsin and chymotrypsin proteases, inhibition of aphid cholinesterase, electron transport 
dysfunction, inhibition of plasma membrane $\mathrm{H}+$ ATPase activity and growth suppression (Houseman et al., 1992; Jabeen et al., 2007; Makowska et al., 2015). The toxic properties of DIBOA, DIMBOA, HBOA, HMBOA, HDMBOA, MBOA and BOA are confirmed in many studies. DIBOA and its methyl derivative DIMBOA are the most studied and most effective BXs against insects, fungi, bacteria, nematodes and weeds (Niemeyer, 2009). Their breakdown products, BOA and MBOA, also show antimicrobial activity (Martyniuk et al., 2006), but are less toxic than DIBOA and DIMBOA (Kumar et al., 1993). Cambier et al. (2001) showed that
HDMBOA had stronger negative effect on survival of the rose-grain aphid (Metopolophium dirhodum Walk.) than DIMBOA. The presence of the hydroxyl group at C-4 in hydroxamic acid and electron-donating hydroxyl or methoxy group in the 7 position of the benzoxazolonones contributed to the increased reactivity of these compounds (Escobar et al., 1999; Springob \& Kutchan, 2009). The lower phytotoxicity of HBOA and HMBOA in comparison to DIBOA and DIMBOA is associated with the absence of the $\mathrm{OH}$ group on position 4 of the oxazinone ring (Huang et al., 2003). Considering the wide scope of BXs defence

Table 1. Benzoxazinoids derivatives and their chemical structure

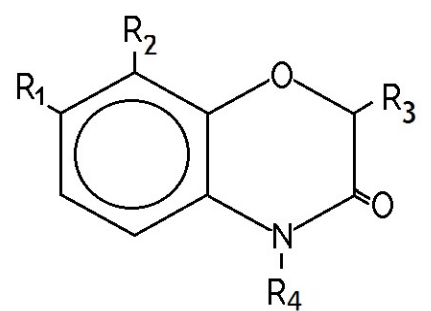

\begin{tabular}{|c|c|c|c|c|c|c|}
\hline $\mathrm{R}_{1}$ & $\mathrm{R}_{2}$ & $\mathrm{R}_{3}$ & $\mathrm{R}_{4}$ & Abbreviation & Chemical name & Class \\
\hline$-\mathrm{OCH}_{3}$ & $-\mathrm{H}$ & $-\mathrm{OH}$ & $-\mathrm{OH}$ & DIMBOA & 2,4-dihydroxy-7-methoxy-1, 4-benzoxazin-3-one & \multirow{5}{*}{ 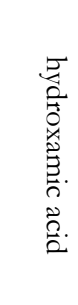 } \\
\hline$-\mathrm{OCH}_{3}$ & $-\mathrm{OCH}_{3}$ & $-\mathrm{OH}$ & $-\mathrm{OH}$ & $\mathrm{DIM}_{2} \mathrm{BOA}$ & 2,4-dihydroxy-7,8-dimethoxy-1,4-benzoxazin-3-one & \\
\hline$-\mathrm{H}$ & $-\mathrm{H}$ & $-\mathrm{OH}$ & $-\mathrm{OH}$ & DIBOA & 2,4-dihydroxy-1,4-benzoxazin-3-one & \\
\hline$-\mathrm{OH}$ & $-\mathrm{H}$ & $-\mathrm{OH}$ & $-\mathrm{OH}$ & TRIBOA & 2,4,7-trihydroxy-1,4-benzoxazin-3-one & \\
\hline$-\mathrm{OH}$ & $-\mathrm{OCH}_{3}$ & $-\mathrm{OH}$ & $-\mathrm{OH}$ & TRIMBOA & 2,4,7-trihydroxy-8-methoxy-1,4-benzoxazin-3-one & \\
\hline$-\mathrm{OCH}_{3}$ & $-\mathrm{H}$ & $-\mathrm{OH}$ & $-\mathrm{H}$ & HMBOA & 2-hydroxy-7-methoxy-1,4-benzoxazin-3-one & \multirow{4}{*}{ 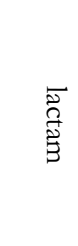 } \\
\hline$-\mathrm{OCH}_{3}$ & $-\mathrm{OCH}_{3}$ & $-\mathrm{OH}$ & $-\mathrm{H}$ & $\mathrm{HM}_{2} \mathrm{BOA}$ & 2-hydroxy-7,8-dimethoxy-1,4-benzoxazin-3-one & \\
\hline$-\mathrm{H}$ & $-\mathrm{H}$ & $-\mathrm{OH}$ & $-\mathrm{H}$ & $\mathrm{HBOA}$ & 2-hydroxy-1,4-benzoxazin-3-one & \\
\hline$-\mathrm{OH}$ & $-\mathrm{H}$ & $-\mathrm{OH}$ & $-\mathrm{H}$ & DHBOA & 2,7-dihydroxy-1,4-benzoxazin-3-one & \\
\hline$-\mathrm{OCH}_{3}$ & $-\mathrm{OCH}_{3}$ & $-\mathrm{OH}$ & $-\mathrm{OCH}_{3}$ & $\mathrm{HDM}_{2} \mathrm{BOA}$ & 2-hydroxy-4,7,8-trimethoxy-1,4-benzoxazin-3-one & \multirow{2}{*}{ 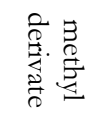 } \\
\hline$-\mathrm{OCH}_{3}$ & $-\mathrm{H}$ & $-\mathrm{OH}$ & $-\mathrm{OCH}_{3}$ & HDMBOA & 2-hydroxy-4,7-dimethoxy-1,4-benzoxazin-3-one & \\
\hline
\end{tabular}

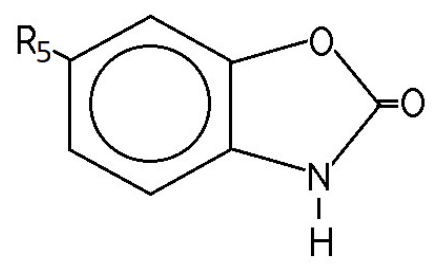

\begin{tabular}{llll}
\hline $\mathrm{R}_{5}$ & Abbreviation & Chemical name & Class \\
\hline$-\mathrm{OCH}_{3}$ & MBOA & 6-methoxybenzoxazolin-2-one & benzoxazolinone \\
$-\mathrm{H}$ & BOA & 2-benzoxazolin-2(3H)-one &
\end{tabular}




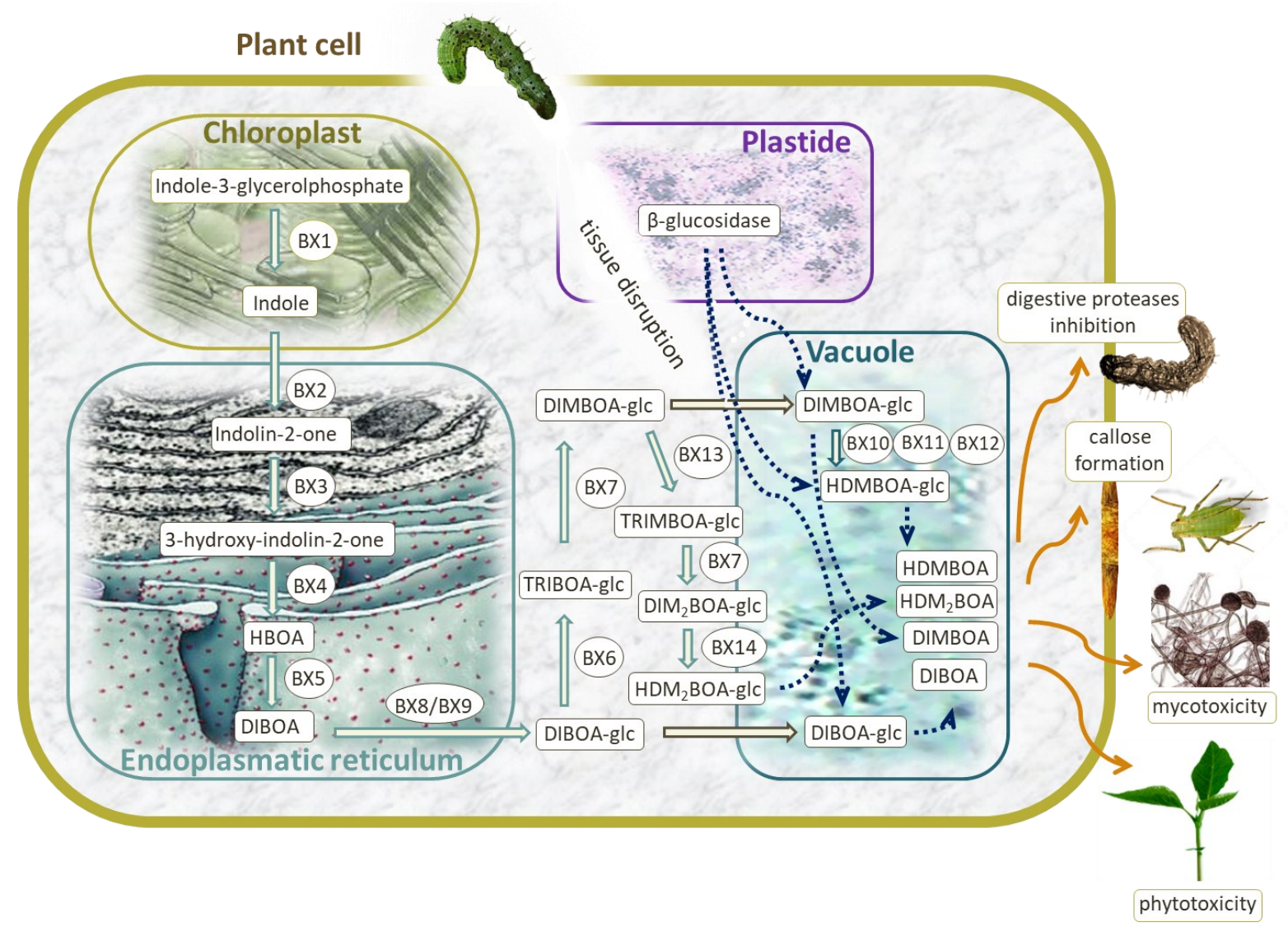

Figure 1. The mechanisms of BX defence against biotic stress and genes involved in BX biosynthesis. Adapted from Dutartre et al. (2012).

responses to various harmful organisms, it can be concluded that BXs act via many different biochemical pathways involved in the defence mechanisms, depending on the complex interaction between the host plant and the pathogen or pest.

Both DIBOA and DIMBOA are unstable compounds, spontaneously degrading in the soil and under physiological aqueous conditions to more stable benzoxazolinones, $\mathrm{BOA}$ and $\mathrm{MBOA}$, respectively (Meyer et al., 2009; Zasada et al., 2005). The rhizosphere microorganisms enable further break-down of the benzoxazolinones to phenoxazinones, chemical compounds that possess stronger antifungal, antibacterial and plant allelopathic properties (Neal et al., 2012). Under different conditions, the hydroxamic acids also degrade to lactams, benzoxazolinones, aminophenoxazines, malonamic acids, aminophenols and acetamidophenols (Oliveros-Bastidas et al., 2012). Apart from hydroxamic acids, the instability was also observed in lactam HDMBOA (Glauser et al., 2011). Like DIMBOA, HDMBOA degraded into MBOA and $\mathrm{BOA}$, but this nonenzymatic breakdown is faster for HDMBOA than DIMBOA (Macías et al., 2004). The second methoxyl group on HDMBOA makes this compound less stable and more reactive than DIMBOA (Maresh et al., 2006). The instability of natural BXs could be a major obstacle considering their practical application in crop protection. Interestingly, the synthetic benzoxazinone analogs, lacking the hydroxyl group at position $\mathrm{C}$-2, were found to have increased stability and phytotoxicity, indicating their potential as agrochemicals (Chinchilla et al., 2015).

Benzoxazionids are phytoanticipins, constitutive chemicals produced during the development of young plants without an external trigger. The concentrations of DIMBOA are the highest in the seedlings and can reach up to $30 \mathrm{mM}$ (Zheng et al., 2015). In addition, the biosynthesis of benzoxazinoids can also be induced by wounding, such as pathogen and insect attack, or treatments with methyl jasmonate or plant elicitor peptides (Dafoe et al., 2013; Huffaker et al., 2013; Oikawa et al., 2004; Wang et al., 2007). Like DIMBOA and DIBOA, the HDMBOA synthesis can be both constitutive and induced (Dafoe et al., 2011; Huffaker et al., 2011).

To avoid autotoxicity, DIMBOA and DIBOA are glycosylated and stored in inactive forms in plant vacuoles, while the enzyme $\beta$-glucosidase required for their activation is located in the plastid (Figure 1). Upon pest or pathogen attack and consequent plant tissue disruption, BX-glucosides, released from damaged vacuoles, are hydrolysed by the $\beta$-glucosidase and the 
toxic aglycons are formed (von Rad et al., 2001).

Both DIMBOA and DIBOA decrease the activity of the enzyme endoprotease in the digestive system of the insect larvae, limiting the availability of amino acids and reducing larval growth leading them to starvation (Houseman et al., 1992). Moreover, the breakdown products of DIMBOA and DIBOA have antifeedant effects on insect (Gierl \& Frey, 2001). Furthermore, as a response to herbivory, pathogen infestation or jasmonic acid treatment, DIMBOA-glucoside is converted to HDMBOA-glucoside (Meihls et al., 2013; Oikawa et al., 2004). The conversion of DIMBOA-glucoside to HDMBOA-glucoside seemed to be related to increased resistance to pathogens and herbivores (Dafoe et al., 2011; Glauser et al., 2011). Like DIMBOA-glucoside, HDMBOA-glucoside can be hydrolysed by glucosidase upon tissue disruption and converted to toxic HDMBOA and its further breakdown products
(Glauser et al., 2011; Maresh et al., 2006; Oikawa et al., 2004).

Beside its toxic properties, DIMBOA also acts by signalling for callose deposition in sieve elements upon aphid attack. In maize, signalling is the main defensive mechanism against aphids and more effective than direct BX toxicity (Maag et al., 2015). It was hypothesised that DIMBOA is a part of phytohormone signalling pathway in maize callose formation by cytokinins degradation, being an electron acceptor for apoplastic cytokinin dehydrogenase (Frébortová et al., 2010). Cytokinins, in turn, repress abscisic acid (ABA). Having the role in cytokinin decline and $\mathrm{ABA}$ increase, DIMBOA contributes to ABA-dependent priming of callose deposition (Ton et al., 2009). Moreover, the callose formation is considerably decreased in $\mathrm{BX}$ deficient $(b \times 1)$ maize inbred lines than in the $B \times 1$ lines that are capable of BX production (Ahmad et al., 2011).

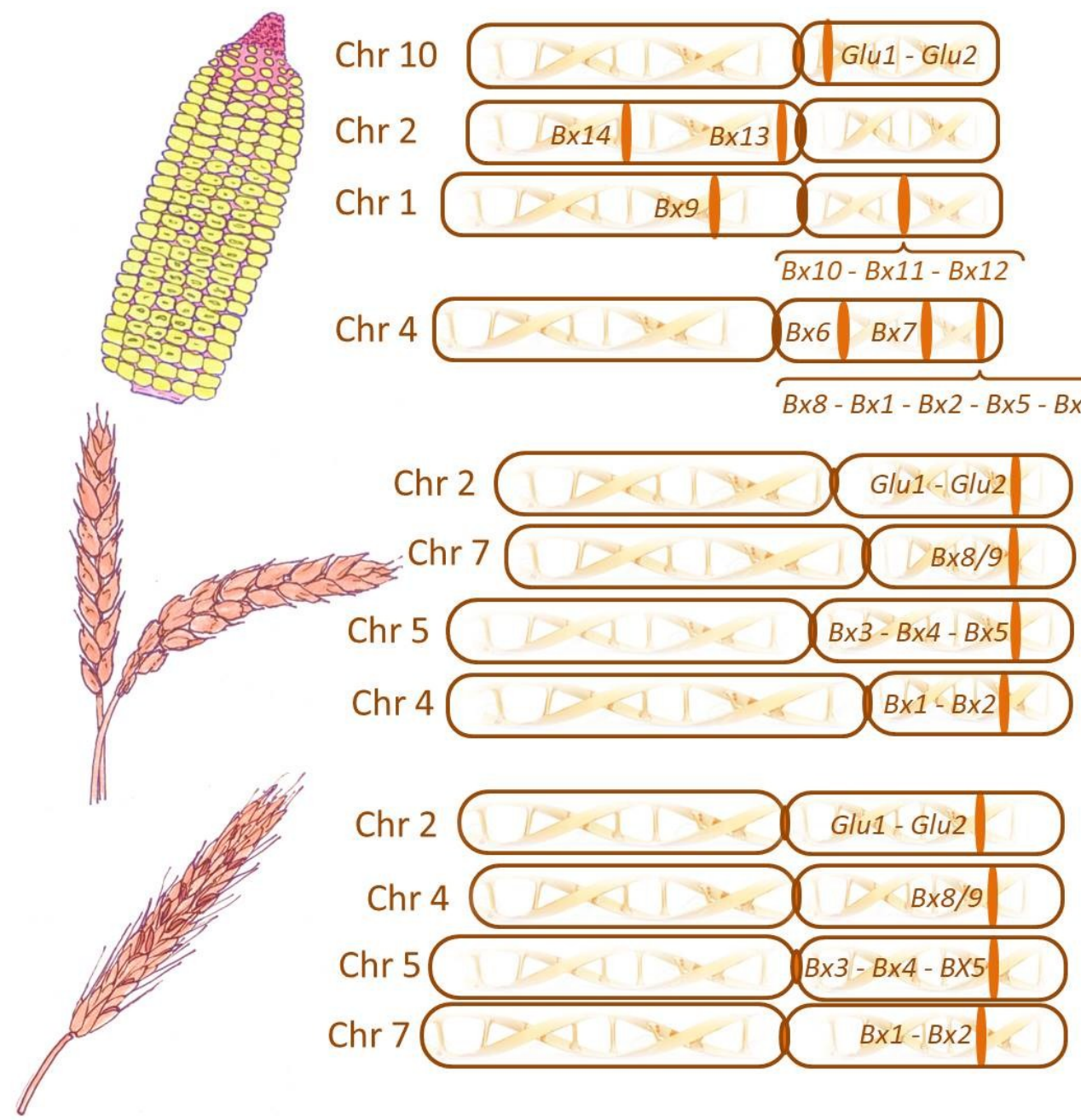

Figure 2. Bx genes in maize, wheat and rye 


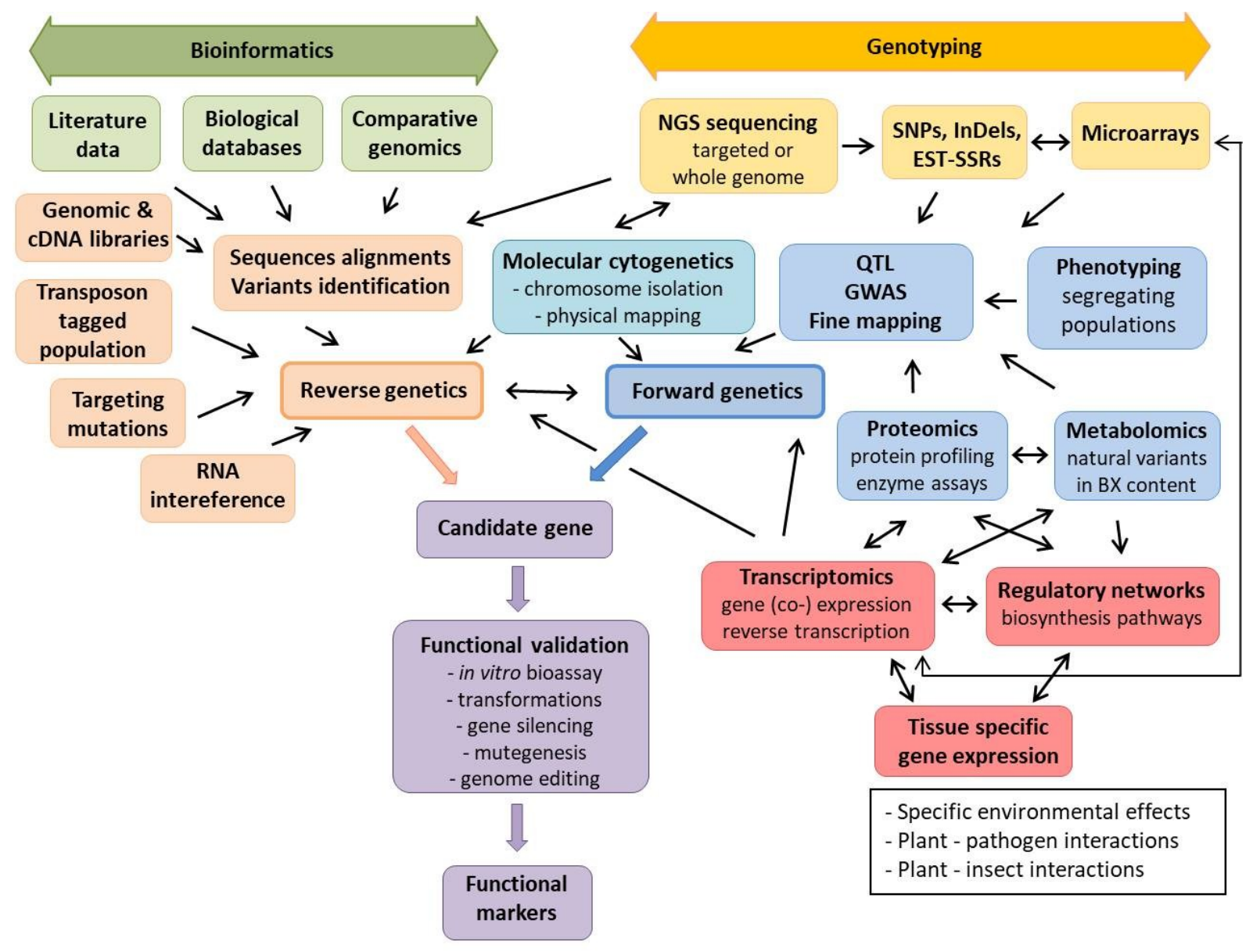

Figure 3. A research scheme for combined use of genetic and "omics" tools for genetic and biochemical characterisation of benzoxazinoids

The infiltration of DIMBOA in apoplast triggered hydrolyses of DIMBOA and its integration into a matrix of callose to provide chemical defence against parasites penetration (Ahmad et al., 2011).

\section{Genetics and biochemistry of benzoxazinoids biosynthesis}

Sixteen genes conferring benzoxazinoids biosynthesis were mapped in maize and nine genes in wheat and rye (Figure 2). In the following paragraphs, the genetics of BXs biosynthesis will be presented on the example of maize, being the crop most studied for this topic, and compared to wheat and rye.

The benzoxazinoids biosynthesis starts in the chloroplast with formation of indole from indole-3glycerol phosphate (Figure 1). This reaction is catalysed by the enzyme indole glycerol phosphate lyase, denoted as BX1. The gene that codes for BX1 enzyme is named BENZOXAZINELESS1 or Bx1 (Frey et al., 1997). Another maize gene, $I g l$, also codes for the same indole glycerol phosphate lyase enzyme that catalysis the same reaction. The difference between these two genes is in their transcriptional regulation; $B \times 1$ is under developmental control and is produced constitutively during the growth of young plants mostly without external signals, whereas the $I g l$ is regulated by induced stress stimuli (Ahmad et al., 2011).

The following enzymatic reactions that hydroxylate indole via the intermediate products to DIBOA take place in the endoplasmic reticulum. The reactions are catalysed by four cytochrome P450-dependent monooxygenases, termed BX2 to BX5, encoded by $B \times 2$ to $B \times 5$ genes (Dick et al., 2012). Toxic and unstable DIBOA is glucosylated in the cytosol to the non-toxic stable form DIBOA-glucoside by the UDPglucosyltransferase $\mathrm{BX} 8$ or $\mathrm{BX} 9$. The conversion of DIBOA to DIBOA-glucoside and DIMBOA to DIMBOA-glucoside are controlled by $B \times 8$ and $B \times 9$ genes (von Rad et al., 2001). The glucosylated DIBOA is converted to TRIBOA by dioxygenase BX6 and then to DIMBOA-glucoside by methyltransferase BX7 in the cytosol. These processes are controlled by $B \times 6$ and $B \times 7$ genes (Jonczyk et al., 2008). Glucosylated forms are then transferred to the plant vacuoles. 
In addition to the $B x$ genes, two more genes, Glu1 and Glu2, on chromosome 10 were found to code for the plastid enzymes $\beta$-glucosidases that convert DIBOA -glucoside or DIMBOA-glucoside to their toxic aglucones (Babcock \& Esen, 1994; Sue et al., 2011). These two genes had long been considered the only isogenes responsible for $\beta$-glucosidase activity in maize. However, Gómez-Anduro et al. (2011) reported 26 Glu genes on all maize chromosomes governing $\beta$ glucosidase activity of 26 isozymes in plastids, vacules, cytosol and mithochondria with tissue, genotype and environment specific expression patterns. Recently, Meihls et al. (2013) identified three methyltransferases regulated by $B \times 10 a-c$ genes on chromosome 1 that convert DIMBOA-glucoside to HDMBOA-glucoside. The existence of multiple $B \times 10$ genes is hypothesised to be related to different responses to various pest and pathogens in different plant tissues (Meilhs et al., 2013). The genes $B \times 10 a, B \times 10 b$ and $B \times 10 c$ were later designated as $B \times 10, B \times 11$ and $B \times 12$ (Handrick et al., 2015). Two more genes involved in $\mathrm{BX}$ biosynthesis were revealed, $B \times 13$ and $B \times 14$, encoding for oxidation of DIMBOA-glucoside to intermediate TRIMBOA- glucoside and conversion of $\mathrm{DIM}_{2} \mathrm{BOA}$-glucoside into $\mathrm{HDM}_{2} \mathrm{BOA}$-glucoside, respectively (Handrick et al., 2015). $\mathrm{DIM}_{2} \mathrm{BOA}$-glucoside and $\mathrm{HDM}_{2} \mathrm{BOA}$-glc were shown to provide resistance to aphids (Handrick et al., 2015). The maize $B \times$ genes (Bx1$B \times 8$ ) cluster close together on the short arm of chromosome 4 , the $B \times 9, B \times 10, B \times 11$ and $B \times 12$ genes are located on chromosome 1 (Frey et al., 2003, Handrick et al., 2015), while $B \times 13$ and $B \times 14$ were mapped on chromosome 2 (Handrick et al., 2015).

The expression pattern of $B x$ genes and concentration of BXs varies across species, plant organ and plant age. In general, the methoxy derivative DIMBOA is more frequent in maize and wheat, whereas DIBOA prevails in rye and wild barley (Hordeum lechleri (Steud.) Schenck) (Niemeyer, 2009).

In maize, the BXs are identified in all plant tissues (Oikawa et al., 2004; Park et al., 2004). The highest expression of $B x$ in maize seedlings is determined 6-10 days after germination after which it starts to decline in areal parts with plant age (Cambier et al., 2000). The concentration of DIMBOA in maize plants required for efficient biological control against European corn borer was estimated to be $1.5 \mathrm{mM}$, which corresponds to about 1 mg g-1 of fresh weight (Campos et al., 1989). Unlike in leaves and stem, BX concentration in maize roots does not change during plant growth and development (Cambier et al., 2000). Moreover, the composition of BXs also changes with time. DIMBOA was found to be predominate in young maize plants, whereas 2-hydroxy-4,7-dimethoxy-1,4benzoxazin-3-one (HDMBOA) was a major hydroxamic acid in old maize plants and roots (Cambier et al. 2000; Huffaker et al., 2011).

Orthologs of the maize genes $B \times 1-B \times 5$ were identified in hexaploid wheat (Nomura et al., 2003), diploid wheat (Triticum boeoticum Boiss.) (Nomura et al.,
2007), rye (Bakera et al., 2015) and wild barley (Grün et al., 2005). It is supposed that the loss of the gene cluster occurred in the cultivated barley (Hordeum vulgare L.) during domestication (Gierl \& Frey, 2001) or as a result of chromosomal rearrangements (Grün et al., 2005).

In wheat, the $B \times 1$ and $B \times 2$ genes are localized on chromosomes 4 , whereas $B \times 3, B \times 4$ and $B \times 5$ are identified on chromosome 5 . The expression of $B x$ genes is unequal in three wheat genomes. The highest transcription activity detected in B genome of hexaploid wheat (Nomura et al., 2005) was congruent with the findings that Aegilops speltoides Tausch, the donor of genome B, had higher transcription level then Triticum urartu Tumanian ex Gandilyan and Aegilops tauschii Coss., donors of genomes $\mathrm{A}$ and $\mathrm{D}$, respectively. The genes encoding glucosylglucosidases (Glu1 and Glu2) and glucosyltransferases $(B \times 8 / B \times 9)$ in hexaploid wheat were identified on chromosomes 2 and 7, respectively (Sue et al., 2011). Wheat leaves accumulate higher concentration of DIMBOA than DIBOA, but the concentration of both hydroxamic acids decrease in latter plant stages. Interestingly, higher concentrations of DIBOA were detected in wheat roots than in leaves (Copaja et al., 1999). Despite decline of BX concentration with plant age, a recent study, revealed upregulation of four genes involved in BX biosynthesis during flag leaf senescence in wheat (Gregersen \& Holm, 2007). The expression of $B x$ in later plant stages is considered to be a result of stress during plant senescence, such as secondary pathogenesis. Besides, environmental conditions, such as photoperiod light intensity and duration can also affect BXs biosynthesis in wheat (Epstein et al., 1986).

The rye chromosome 7 carries $B \times 1$ and $B \times 2$ genes, whereas $B \times 3-B \times 5$ genes are clustered on the chromosome 5 (Nomura et al., 2003). The genes encoding glucosylglucosidases and glucosyltransferases were mapped to rye chromosomes 2 and 4 (Sue et al., 2011). The genes $B \times 6$ and $B \times 7$, present in maize, were not found in wheat or wild barley. Recently, Tanwir et al. (2017) identified and characterised ScBX6-like enzyme in rye to be a functional ortholog of maize $B \times 6$. In rye, nonmethoxylated BXs, such as DIBOA, were found to be prevalent in aboveground plant parts, whereas nonmethoxylated BXs, such as DIMBOA, were detected in higher concentrations in roots (Rice et al., 2005; Tanwir et al., 2017). Newly, characterised ScBx6-like gene showed contrasting expression pattern comparing to five previously mapped genes $S c B \times 1-5$. It was more expressed in roots than in shoots and more expressed at later stages that other ScBx genes (Tanwir et al., 2017).

Although the genes controlling BX biosynthesis were identified in wild barley (Grün et al., 2005); they have not been yet mapped to a known genomic location (Sue et al., 2011).

The study of Devos (1993) determined a synteny between the rye chromosome 7 and the wheat chromosome 4 , where the $B \times 1$ and $B \times 2$ genes are mapped, as well as between the rye and the wheat chromosomes 5 
with $B \times 3$ and $B \times 4$ genes. Moreover, a synteny between the short arm of the maize chromosome 4 and the wheat chromosome 5 was also found (Gale \& Devos, 1998). Comparing wheat, rye and maize genomes, the evolutionary studies revealed a monophyletic origin of BX gene cluster, i.e. derived from a common ancestor (Dutartre et al., 2012; Salse et al., 2009). The B×1 gene evolved from the duplication of the gene encoding for alpha-subunit of tryptophan synthase (Grün et al., 2005), whereas $B \times 2$ to $B \times 5$ arose from duplications and specialisation of an unknown ancestral CYP71C gene (Dutartre et al., 2012). The origin of the other $B x$ genes is less clear. The $B \times 9$ reveal as a recent duplicate of $B \times 8$ in the phylogenetic analysis of Sue et al. 2011. The Glu genes, encoding enzymes glucosidases in monocots and dicots, underwent convergent evolution from homolog nonortholog genes that evolved specificity to benzoxazinoids as substrates (Dick et al., 2012). The gene clustering was explained as a mean of transferring genes between relative species during evolution, sharing the same biochemical pathways (Nomura et al., 2003), and facilitating coordinated gene regulation (Frey et al., 2009).

\section{The unknown requiring further research}

The several benzoxazinoid mapping studies identified QTLs (Quantitative Trait Loci) contributing to the BX accumulation and pest resistance, on the chromosomes that were not previously known to harbour $B x$ genes (Betsiashvili et al., 2015; Butrón et al., 2010). Whether these QTLs have a role in biosynthesis or regulation of BX pathway it is yet to be revealed. Besides, it is still unknown which genes and enzymes are involved in the transformation of DIBOA-glucoside to DIMBOAglucoside in wheat and partially in rye. Moreover, the exact gene locations of some $B x$ genes are still to be found. Another question is what are the factors that regulate $B x$ genes expression in different tissues and at different stages of plant development and how are they regulated by different biotic and abiotic stresses. Finally, from the practical viewpoint, it would be of a great interest to identify those polymorphisms that are functionally relevant to BX biosynthesis. Current technological advances and new experimental approaches provide plant researchers with powerful tools to address these unresolved questions. Possible directions of further research and the choice of specific methodologies would, by all means, differ for each of the questions. In Figure 3, we propose some approaches that may be pursued to elucidate unknown genetic and biochemical components that underlay BXs synthesis.

The QTL mapping studies, both linkage and association mapping, are employed to identify genetic factors in QTL regions that are responsible for phenotypic variation in a segregating mapping population. The mapping population in linkage mapping is developed from a bi-parental cross, usually as an $\mathrm{F}_{2}$, doubled haploid, backcross or recombinant inbred lines population. Conversely, the association analysis uses natural variation of a diverse population of unrelated individuals and may be based on a candidate gene approach or a whole-genome study. If a QTL identified in a mapping study has not been previously linked to a chromosome locus known to harbour $B x$ genes or other characterised genetic factor contributing to a trait variation, then the putative QTL needs to be dissected to a candidate gene or a regulatory sequence, which should be further annotated and its function validated. Firstly, a large chromosomal segment encompassing the identified QTL is to be narrowed down to much shorter interval by fine mapping, using a population developed from a cross between near isogenic lines differing only in a segment containing the QTL. The region of interest should be saturated with high number of markers, such as simple sequence repeats (SSRs), insertion-deletions (InDels) or single nucleotide polymorphisms (SNPs). Due to their abundance throughout a genome and their suitability for high-throughput automation, SNPs became the markers of choice for most genotyping systems. SNPs can be developed from express sequence tag sequences or next generation sequencing (NGS) data and are often utilized for genotyping in a SNP chip or microarray. Although phenotyping segregation population for susceptibility or tolerance to biotic stress may certainly be a valuable additional guidepost, phenotyping in a QTL mapping for BXs implies metabolite, protein (i.e. enzyme) and/or transcription analyses. If a referent genome sequence is available for the species, the markers found to flank the QTL by fine mapping are used to define a referent sequence segment that should be screened for open reading frames (ORFs) in order to design primers. If, however, a referent sequence is not available in a database, ORFs identification and primers design can be obtained from the tedious chromosome walking using bacterial artificial chromosome (BAC) libraries or assumed from available referent genome of another phylogenetically related species. The amplified PCR products are cloned and sequenced and a candidate gene sequence is inferred using bioinformatics tools. When a sequence of the candidate gene is known, it can be used as a probe to find physical location of the gene on chromosome(s) applying fluorescence in situ hybridisation technique.

Rapid advancement of modern analytic techniques for transcript, protein and metabolite profiling enables highthroughput complementary analyses of genes, proteins, metabolites and their interactions in BX biosynthesis and regulation of defence mechanisms. Transcriptional profiling of a mapping population may reveal a range of differently expressed genes each of which can be observed as a quantitative trait and subjected to a QTL analysis. Microarrays and RNA sequencing can generate abundant data on gene co-expression and elucidate gene regulatory networks in specific stress conditions, plantinsect or plant-pathogen interactions and during different plant developmental stages. In addition, highthroughput protein-protein interactions analyses can help infer biological processes underlying plant resistance. Combining transcriptomics and proteomics 
with high-throughput metabolomics techniques for detection and quantification of different BX metabolites, such as mass spectrometry (MS), liquid chromatography-mass spectrometry (LC-MS), gas chromatography-mass spectrometry (GC-MS) and nuclear magnetic resonance (NMR), could facilitate prediction and validation of new candidate genes function. An example of successful integration of different techniques in identifying candidate genes is a study of Liu et al. (2103), who detected cold tolerant genes in rice combining QTL-mapping and microarray analysis.

If genes are identified in some species but not in those relating to them, such as, for example, the genes $B \times 6$ and $B \times 7$, controlling the transformation of DIBOA -glucoside to DIMBOA-glucoside in maize, but absent in wheat and wild barley, reverse genetics may be more appropriate strategy for further research. The known gene sequence obtained from the literature or public repositories can be used to search other species databases or sequenced libraries for similar sequence. Nucleotide or protein sequence comparison enables molecular function annotation based in their similarity with certain accuracy. The selected candidate sequence or gene can be then amplified with PCR using primers designed based on the identified sequence in the database, cloned and sequenced. The identification of gene function can be achieved by comparing phenotypes of wild-type genotypes with mutants obtained by transposon-tagging, targeting mutation, RNA interference or similar reverse genetics methods. A transposon-tagged population for barley is developed based on maize Activator/Dissociation transposable elements that may overexpress or inactivate genes (Ayliffe \& Prrior, 2011). For hexaploid wheat, development of an efficient tagging system is hampered due to gene redundancy from homeolog chromosomes that might be overcome by developing recessive mutations on all homeologs (Ayliffe \& Prrior, 2007). Targeting induced local lesions in genome (TILLING) is another strategy that may be applied to create high number of recessive single base mutations in targeted sequences and to identify non-functional proteins the mutations caused. When mutant alleles are not available, gene function can be inferred by RNA interference, silencing gene expression and analysing its effect on plant phenotype. The research should be extended to regulatory non-coding regions that could also cause variation in BX phenotypes.

The functional candidate gene characterisation is a crucial step in validation of the inferred function of the gene and its product. The gene may be cloned and expressed in a host organism e.g. Escherichia coli, its enzyme purified and analysed for biochemical activity in vitro. Furthermore, reverse genetics tools could be used to make targeted changes in the gene, by overexpressing or silencing it. This can be done through RNA silencing, genetic transformation, mutagenesis or genome editing.
Groszyk et al. (2017) were the first to use virus induced gene silencing technique, based on targeted posttranscriptional gene silencing, to analyse and validate the function of the rye ortholog of maize $B \times 1$ gene. This technique proved to be suitable for species that are recalcitrant to transformation, which genome has not been sequenced, or with no mutant populations available. Linking sequence polymorphism in characterised $B x$ genes with variations in BX content in a number of distinct phenotypes is a prerequisite for development of functional DNA markers associated with the BXs production. Using this approach, Butrón et al. (2010) identified a haplotype (allele combination) for a SNP and a InDel in the $B \times 1$ gene that contributed most to total DIMBOA content and maize inbred lines that carried this allele combination. This information on the exact position and nature of genetic variation that contribute to high DIMBOA content can be readily used in developing functional markers. Once generated from gene sequences, functional markers ought to be reliable and very useful when identifying favourable alleles and allelic combinations for BX content in cereal breeding. Marker-assisted selection using functional markers would greatly facilitate exploiting genetic resources in breeding programmes, as a genepool of resistance for developing new cereal varieties with high $\mathrm{BX}$ content resistant to a wider range of pest organisms.

\section{Conclusions}

For long, benzoxazinoids have been well-known as natural plant components that play an important role in plant defence against biotic stress. Yet, the ability of many cereal species to produce BXs has a great untapped potential for its practical application in cereal protection and breeding, which propels the need for a much better understanding of genetic and biochemical bases underlying BX defence mechanisms, essential to fully exploit their potential. Recent rapid advancements in genetic and genomics tools have significantly contributed to elucidating the BX genetic control. The constant trend of cost reduction of large-scale high throughput analyses may considerably enable researchers to give much thorough answers to the still unresolved questions and implement their findings in diverse farming systems.

\section{References}

Ahmad, S., Veyrat, N., Gordon-Weeks, R., Zhang, Y., Martin, J., Smart, L., Glauser, G., Merb, M., Flors, V., Frey, M., \& Ton, J. (2011). Benzoxazinoid metabolites regulate innate immunity against aphids and fungi in maize. Plant Physiology, 157(1), 317-327.

Ayliffe, M. A., \& Pryor, A. J. (2007). Activation tagging in plants generation of novel, gain-of-function mutations. Australian Journal of Agricultural Research, 58, 490-497.

Ayliffe, M. A., \& Pryor, A. J. (2011). Activation tagging and insertional mutagenesis in barley. Methods in Molecular Biology, 678, 107-128.

Babcock, G. D., \& Esen, A. (1994). Substrate specificity of maize bglucosidase. Plant Science, 101, 31-39. 
Bakera, B., Makowska, B., Groszyk, J., Niziołek, M., Orczyk, W., Bolibok-Bragoszewska, H., Hromada-Judycka, A., \& RakoczyTrojanowska, M. (2015). Structural characteristics of ScBx genes controlling the biosynthesis of hydroxamic acids in rye (Secale cereale L.). Journal of Applied Genetics, 56(3), 287-298.

Betsiashvili, M., Ahern, K. R., \& Jander, G. (2015). Additive effects of two quantitative trait loci that confer Rhopalosiphum maidis (corn leaf aphid) resistance in maize inbred line Mo17. Journal of Experimental Botany, 66(2), 571-578.

Butrón, A., Chen, Y. C., Rottinghaus, G. E., \& McMullen, M. D. (2010). Genetic variation at bx1 controls DIMBOA content in maize. Theoretical and Applied Genetics, 120(4), 721-734.

Cambier, V., Hance, T., \& De Hoffmann, E. (2000). Variation of DIMBOA and related compounds content in relation to the age and plant organ in maize. Phytochemistry, 53, 223-229.

Cambier, V., Hance, T., \& De Hoffmann, E. (2001). Effects of 1, 4benzoxazin-3-one derivatives from maize on survival and fecundity of Metopolophium dirhodum (Walker) on artificial diet. Journal of Chemical Ecology, 27(2), 359-370.

Campos, F., Atkinson, J., Arnason, J. T., Philogene, B. J. R., Morand, P., Werstiuk, N. H., \& Timmins, G. (1989). Toxicokinetics of 2,4dihydroxy-7-methoxy-1,4-benzoxazin-3-one (DIMBOA) in the European corn borer, Ostrinia nubilalis (Hübner). Journal of Chemical Ecology, 15, 1989-2001.

Chinchilla, N., Marín, D., Oliveros-Bastidas, A., Molinillo, J. M., \& Macías, F. A. (2015). Soil biodegradation of a benzoxazinone analog proposed as a natural products-based herbicide. Plant and Soil, 393(1-2), 207-214.

Copaja, S. V., Nicol, D., \& Wratten, S. D. (1999). Accumulation of hydroxamic acids during wheat germination. Phytochemistry, 50(1), 17-24.

Dafoe, N. J., Huffaker, A., Vaughan, M. M., Duehl, A. J., Teal, P. E., \& Schmelz, E. A. (2011). Rapidly induced chemical defenses in maize stems and their effects on short-term growth of Ostrinia nubilalis. Journal of Chemical Ecology, 37(9), 984-991.

Dafoe, N. J., Thomas, J. D., Shirk, P. D., Legaspi, M. E., Vaughan, M. M., Huffaker, A., Teal, P. E., \& Schmelz, E. A. (2013). European corn borer (Ostrinia nubilalis) induced responses enhance susceptibility in maize. PloS ONE, 8(9), e73394.

Devos, K. M., Atkinson, M. D., Chinoy, C. N., Francis, H. A., Harcourt, R. L., Koebner, R. M. D., Liu, C. J., Masojć, P., Xie, D. X., \& Gale, M. D. (1993). Chromosomal rearrangements in the rye genome relative to that of wheat. Theoretical and Applied Genetics, 85(6-7), 673-680.

Dick, R., Rattei, T., Haslbeck, M., Schwab, W., Gierl, A., \& Frey, M. (2012). Comparative analysis of benzoxazinoid biosynthesis in monocots and dicots: independent recruitment of stabilization and activation functions. The Plant Cell, 24(3), 915-928.

Dutartre, L., Hilliou, F., \& Feyereisen, R. (2012). Phylogenomics of the benzoxazinoid biosynthetic pathway of Poaceae: gene duplications and origin of the Bx cluster. BMC Evolutionary Biology, 12(1), 1-19.

Epstein, W. W., Rowsemitt, C. N., Berger, P. J., \& Negus, N. C. (1986). Dynamics of 6-methoxybenzoxazolinone in winter wheateffects of photoperiod and temperature. Journal of Chemical Ecology, 12, 2011-2020.

Escobar, C. A., Sicker, D., \& Niemeyer, H. M. (1999). Evaluation of DIMBOA analogs as antifeedants and antibiotics towards the aphid Sitobion avenae in artificial diets. Journal of Chemical Ecology, 25 (7), 1543-1554.

Frébortová, J., Novák, O., Frébort, I., \& Jorda, R. (2010). Degradation of cytokinins by maize cytokinin dehydrogenase is mediated by free radicals generated by enzymatic oxidation of natural benzoxazinones. The Plant Journal, 61(3), 467-481.

Frey, M., Chomet, P., Glawischnig, E., Stettner, C., Grün, S., Winklmair, A., Eisenreich, W., Bacher, A., Meeley, R. B., Briggs, S. P., Simcox, K., \& Simcox, K. (1997). Analysis of a chemical plant defense mechanism in grasses. Science, 277(5326), 696-699.

Frey, M., Huber, K., Park, W. J., Sicker, D., Lindberg, P., Meeley, R. B., Smmons, C. R., Yalpani, N., \& Gierl, A. (2003). A 2 oxoglutarate-dependent dioxygenase is integrated in DIMBOA biosynthesis. Phytochemistry, 62(3), 371-376.

Gale, M. D., \& Devos, K. M. (1998). Comparative genetics in the grasses. Proceedings of the National Academy of Sciences of the U.S.A., 95(5), 1971-1974.
Gierl, A., \& Frey, M. (2001). Evolution of benzoxazinone biosynthesis and indole production in maize. Planta, 213(4), 493-498.

Glauser, G., Marti, G., Villard, N., Doyen, G. A., Wolfender, J. L., Turlings, T. C., \& Erb, M. (2011). Induction and detoxification of maize 1, 4-benzoxazin-3-ones by insect herbivores. The Plant Journal, 68(5), 901-911.

Gómez-Anduro, G., Ceniceros-Ojeda, E. A., Casados-Vázquez, L. E., Bencivenni, C., Sierra-Beltrán, A., Murillo-Amador, B., \& Tiessen, A. (2011). Genome-wide analysis of the beta-glucosidase gene family in maize (Zea mays L. var B73). Plant Molecular Biology, 77(1-2), 159-183.

Gregersen, P. L., \& Holm, P. B. (2007). Transcriptome analysis of senescence in the flag leaf of wheat (Triticum aestivum L.). Plant Biotechnology Journal, 5, 192-206.

Groszyk, J., Kowalczyk, M., Yanushevska, Y., Stochmal, A., RakoczyTrojanowska, M., \& Orczyk, W. (2017). Identification and VIGSbased characterization of $\mathrm{Bx} 1$ ortholog in rye (Secale cereale $\mathrm{L}$.). PloS ONE, 12(2), e0171506.

Grün, S., Frey, M., \& Gierl, A. (2005). Evolution of the indole alkaloid biosynthesis in the genus Hordeum: distribution of gramine and DIBOA and isolation of the benzoxazinoid biosynthesis genes from Hordeum lechleri. Phytochemistry, 66(11), 1264-1272.

Handrick, V., Robert, C. A., Ahern, K. R., Zhou, S., Machado, R. A., Maag, D., Glauser G., Fernandez-Penny, F. E., Chandran, J. N., Rodgers-Melnik, E., Schneider, B., Buckler, E. S., Boland, W., Gershenzon, J., Jander, G., Erb, M. \& Köllner, T. G. (2016). Biosynthesis of 8-O-methylated benzoxazinoid defense compounds in maize. The Plant Cell, 28(7), 1682-1700.

Houseman, J. G., Campos, F., Thie, N. M. R., Philogene, B. J. R., Atkinson, J., Morand, P., \& Arnason, J. T. (1992). Effect of the maize-derived compounds DIMBOA and MBOA on growth and digestive processes of European corn borer (Lepidoptera: Pyralidae). Journal of Economic Entomology, 85(3), 669-674.

Huang, Z., Haig, T., Wu, H., An, M. \& Pratley, J. (2003). Correlation between phytotoxicity on annual ryegrass (Lolium rigidum) and production dynamics of allelochemicals within root exudates of an allelopathic wheat. Journal of Chemical Ecology, 29, 2263-2279.

Huffaker, A., Dafoe, N. J., \& Schmelz, E. A. (2011). ZmPep1, an ortholog of Arabidopsis elicitor peptide 1, regulates maize innate immunity and enhances disease resistance. Plant Physiology, 155(3), 1325-1338.

Huffaker, A., Pearce, G., Veyrat, N., Erb, M., Turlings, T. C., Sartor, R., Shen, Z., Briggs, S. P., Vaughan, M. M., Alborn, H. T., \& Teal, P. E. (2013). Plant elicitor peptides are conserved signals regulating direct and indirect antiherbivore defense. Proceedings of the National Academy of Sciences of the U.S.A., 110(14), 5707-5712.

Jabeen, R., Yamada, K., Hasegawa, T., Minami, E., Shigemori, H., \& Hasegawa, K. (2007). Direct involvement of benzoxazinoids in the growth suppression induced by phototropic stimulation in maize coleoptiles. Heterocycles, 71(3), 523-529.

Jonczyk, R., Schmidt, H., Osterrieder, A., Fiesselmann, A., Schullehner, K., Haslbeck, M., Sicker, D., Hofmann, D., Yalpani, N., Simmons, C., \& Frey, M. (2008). Elucidation of the final reactions of DIMBOA-glucoside biosynthesis in maize: characterization of $\mathrm{Bx} 6$ and Bx7. Plant Physiology, 146(3), 1053-1063.

Kumar, P., Gagliardo, R. W., \& Chilton, W. S. (1993). Soil transformation of wheat and corn metabolites MBOA and DIM2BOA into aminophenoxazinones. Journal of Chemical Ecology, 19(11), 2453-2461.

Liu, F., Xu, W., Song, Q., Tan, L., Liu, J., Zhu, Z., Fu, Y., Su, Z., \& Sun, C. (2013). Microarray-assisted fine-mapping of quantitative trait loci for cold tolerance in rice. Molecular Plant, 6(3), 757-767.

Maag, D., Erb, M., Köllner, T. G., \& Gershenzon, J. (2015). Defensive weapons and defense signals in plants: Some metabolites serve both roles. BioEssays, 37(2), 167-174.

Macías, F. A., Oliveros-Bastidas, A., Marín, D., Castellano, D., Simonet, A. M., \& Molinillo, J. M. (2004). Degradation studies on benzoxazinoids. Soil degradation dynamics of 2, 4-dihydroxy-7methoxy-(2 H)-1, 4-benzoxazin-3 (4 H)-one (DIMBOA) and its degradation products, phytotoxic allelochemicals from Gramineae. Journal of Agricultural and Food Chemistry, 52(21), 64026413. 
Macías, F. A., Chinchilla, N., Arroyo, E., Molinillo, J. M., Marin, D., \& Varela, R. M. (2010). Combined strategy for phytotoxicity enhancement of benzoxazinones. Journal of Agricultural and Food Chemistry, 58(3), 2047-2053.

Makowska, B., Bakera, B., \& Rakoczy-Trojanowska, M. (2015). The genetic background of benzoxazinoid biosynthesis in cereals. Acta Physiologiae Plantarum, 37(9), 1-12.

Maresh, J., Zhang, J., \& Lynn, D. G. (2006). The innate immunity of maize and the dynamic chemical strategies regulating twocomponent signal transduction in Agrobacterium tumefaciens. ACS Chemical Biology, 1(3), 165-175.

Martyniuk, S., Stochmal, A., Macías, F. A., Marín, D., \& Oleszek, W. (2006). Effects of some benzoxazinoids on in vitro growth of Cephalosporium gramineum and other fungi pathogenic to cereals and on Cephalosporium stripe of winter wheat. Journal of Agricultural and Food Chemistry, 54(4), 1036-1039.

Meihls, L. N., Handrick, V., Glauser, G., Barbier, H., Kaur, H., Haribal, M. M., Lipka, A. E., Gershenzon, J., Buckler, E.S., Erb, M., \& Köllner, T. G. (2013). Natural variation in maize aphid resistance is associated with 2, 4-dihydroxy-7-methoxy-1, 4benzoxazin-3-one glucoside methyltransferase activity. The Plant Cell, 25(6), 2341-2355.

Meyer, S. L., Rice, C. P., \& Zasada, I. A. (2009). DIBOA: Fate in soil and effects on root-knot nematode egg numbers. Soil Biology and Biochemistry, 41(7), 1555-1560.

Neal, A. L., Ahmad, S., Gordon-Weeks, R., \& Ton, J. (2012). Benzoxazinoids in root exudates of maize attract Pseudomonas putida to the rhizosphere. PLOS ONE, 7(4), e35498.

Niemeyer, H. M. (2009). Hydroxamic acids derived from 2-hydroxy2H-1,4-benzoxazin-3(4H)-one: key defense chemicals of cereals. Journal of Agricultural and Food Chemistry, 57, 1677-1696.

Nomura, T., Ishihara, A., Imaishi, H., Ohkawa, H., Endo, T. R., \& Iwamura, H. (2003). Rearrangement of the genes for the biosynthesis of benzoxazinones in the evolution of Triticeae species. Planta, 217(5), 776-782.

Nomura, T., Ishihara, A., Yanagita, R. C., Endo, T. R., \& Iwamura, H. (2005). Three genomes differentially contribute to the biosynthesis of benzoxazinones in hexaploid wheat. Proceedings of the National Academy of Sciences of the U.S.A., 102(45), 16490-16495.

Nomura, T., Ishihara, A., Iwamura, H., \& Endo, T. R. (2007). Molecular characterization of benzoxazinone-deficient mutation in diploid wheat. Phytochemistry, 68(7), 1008-1016.

Oikawa, A., Ishihara, A., Tanaka, C., Mori, N., Tsuda, M., \& Iwamura, H. (2004). Accumulation of HDMBOA-Glc is induced by biotic stresses prior to the release of $\mathrm{MBOA}$ in maize leaves. Phytochemistry, 65(22), 2995-3001.
Oliveros-Bastidas, A., Macías, F. A., Marin, D., Molinillo, J. M., Barbosa, L. C. A., \& Demuner, A. J. (2012). Kinetics and mechanism of the degradation in soil of 2-hydroxy- $(2 \mathrm{H})-1,4-$ benzoxazin-3(4H)-one (HBOA), phytotoxic allelochemicals from gramineae. Avances en Ciencias e Ingeniería, 3, 47-67.

Park, W. J., Hochholdinger, F., \& Gierl, M. (2004). Release of the benzoxazinoids defense molecules during lateral- and crown root emergence in Zea mays. Journal of Plant Physiology, 161, 981-985.

von Rad, U., Hüttl, R., Lottspeich, F., Gierl, A., \& Frey, M. (2001). Two glucosyltransferases are involved in detoxification of benzoxazinoids in maize. The Plant Journal, 28(6), 633-642.

Rice, C. P., Park, Y. B., Adam, F., Abdul-Baki, A. A., \& Teasdale, J. R. (2005). Hydroxamic acid content and toxicity of rye at selected growth stages. Journal of Chemical Ecology, 31, 1887-1905.

Salse, J., Abrouk, M., Bolot, S., Guilhot, N., Courcelle, E., Faraut, T. Waugh, R., Close, T. J., Messing, J., \& Feuillet, C. (2009). Reconstruction of monocotelydoneous proto-chromosomes reveals faster evolution in plants than in animals. Proceedings of the National Academy of Sciences of the U.S.A., 106(35), 14908-14913.

Springob, K., \& Kutchan, T. M. (2009). Introduction to the different classes of natural products. In Plant-Derived Natural Products (pp. 3 -50). Springer US.

Sue, M., Nakamura, C., \& Nomura, T. (2011). Dispersed benzoxazinone gene cluster: molecular characterization and chromosomal localization of glucosyltransferase and glucosidase genes in wheat and rye. Plant Physiology, 157(3), 985-997.

Tanwir, F., Dionisio, G., Adhikari, K. B., Fomsgaard, I. S., \& Gregersen, P. L. (2017). Biosynthesis and chemical transformation of benzoxazinoids in rye during seed germination and the identification of a rye Bx6-like gene. Phytochemistry, 140, 95-107.

Ton, J., Flors, V., \& Mauch-Mani, B. (2009). The multifaceted role of ABA in disease resistance. Trends in Plant Science, 14(6), 310-317.

Wang, J. W., Xu, T., Zhang, L. W., Zhong, Z. M., \& Luo, S. M. (2007). Effects of methyl jasmonate on hydroxamic acid and phenolic acid content in maize and its allelopathic activity to Echinochloa crusgalli (L.). Allelopathy Journal, 19(1), 161.

Zasada, I. A., Meyer, S. L. F., Halbrendt, J. M., \& Rice, C. (2005). Activity of hydroxamic acids from Secale cereale against the plantparasitic nematodes Meloidogyne incognita and Xiphinema americanum. Phytopathology, 95(10), 1116-1121.

Zheng, L., McMullen, M. D., Bauer, E., Schön, C. C., Gierl, A., \& Frey, M. (2015). Prolonged expression of the BX1 signature enzyme is associated with a recombination hotspot in the benzoxazinoid gene cluster in Zea mays. Journal of Experimental Botany, 66(13), 3917-3930.

\section{Benzoksazinoidi - zaštitni sekundarni metaboliti žitarica: Biohemija and genetička kontrola}

\section{Sanja Mikić · Shakoor Ahmad}

Sažetak: Benzoksazinoidi (1,4-benzoksazin-3(4H)-on derivati) su sekundarni metaboliti biljaka koji, u njihovim ranim fazama rasta, igraju važnu ulogu u otpornosti prema štetnim insektima, gljivama, bakterijama i nematodama, i u suzbijanju korova (alelopatiji). Ova biohemijska jedinjenja prisutna su kod nekih članova porodice Poaceae i detaljnije su proučena kod kukuruza (Zea mays L.), pšenice (Triticum aestivum L.) i raži (Secale cereale L.). Najdelotvorniji alelopatski benzoksaziniodi su 2,4-dihidroksi-7-metoksi-2H-1,4-benzoksazin-3(4H)-on (DIMBOA) i 2,4-dihidroksi1,4-benzoksazin-3-on (DIBOA), koji se klasifikuju kao hidroksamske kiseline. Sa ciljem da ukaže na značaj benzoksazinoida u odbrambenim mehanizmima biljaka i njihovu moguću primenu u zaštiti žitarica, ovaj pregledni rad sažima dosadašnja otrića o genetičkog kontroli, biohemijskim putevima, i načinu delovanja ovih sekundarnih metabolita i ukazuje na nerazjašnjena pitanja koja se odnose na benzoksazinoide.

Ključne reči: benzoksazinoidi, biohemijski putevi, DIMBOA, genetička kontrola, kukuruz, odbrambeni mehanizmi biljaka, otpornost, pšenica, raž, sekundarni metaboliti 